\title{
Identification and Utilization of Polymorphic SSR Markers for Genetic Diversity Studies in Oil Palm
}

\author{
H.P. Bhagya ${ }^{1 *}$, B. Kalyana Babu ${ }^{1}$, Mahanthesha B.N. Naika ${ }^{2}$, R.K. Mathur ${ }^{1}$, \\ P.M. Gangadharappa ${ }^{3}$, D. Satisha ${ }^{2}$ and R.B. Naik ${ }^{4}$ \\ ${ }^{1}$ ICAR-Indian Institute of Oil palm Research, Pedavegi, West Godavari District, \\ Andhra Pradesh, India \\ ${ }^{2}$ Kittur Rani Channamma College of Horticulture, Arabhavi-591218 UHS, Bagalkot, \\ Karnataka, India \\ ${ }^{3}$ College of Horticulture, Munirabad, UHS, Bagalkot, Karnataka, India \\ ${ }^{4}$ RHREC, Kumbapur, Dharwad, Karnataka, India \\ *Corresponding author
}

\begin{abstract}
A B S T R A C T
Oil palm (Elaeis guineensis Jacq.) having chromosome number $2 \mathrm{n}=32$ and belongs to the family Arecaceae and it is a rich source of perennial vegetable-oil in India. To sustain the edible oil requirement in the country, oil palm is one of the best options due to its high oil-

Keywords yield (4-6 t/ha) potential compared to other annual oil-yielding crops. Polymorphic simple

Cluster, Elaeis guineensis, sequence repeat (SSR) markers play an important role in genetic diversity and mapping studies in a crop like oil palm. In the present study, total eight genotypes were screened using 110 SSR markers. With of these, 42 were found to be polymorphic and 68 were Genotypes, Molecular, PIC monomorphic and the number of alleles ranged from two to six. The highest Polymorphism Information Content (PIC) value was observed with the primer, Article Info

Accepted:

04 March 2018

Available Online:

10 April 2018

mEgCIR0779 (0.76), while the lowest with mEgCIR3288 (0.11), at an average value of 0.38. Genetic diversity ranged from 0.12 (mEgCIR3288) to 0.79 (mEgCIR0779), with an average value of 0.45 . Based on PIC and other genetic parameters, four highlypolymorphic markers, viz., mEgCIR0779, mEgCIR0782, mEgCIR2347 and mEgCIR2595 were identified. The identified polymorphic SSR loci can be effectively used in mapping and genetic diversity studies of oil palm crop improvement programme. Totally 42 polymorphic SSRs identified and grouped the eight genotypes into two major clusters and the clustering pattern observed was that based on geographical origin.
\end{abstract}

\section{Introduction}

Oil palm (Elaeis guineensis Jacq.) known for its rich source of perennial vegetable-oil in India and it belongs to the Arecaceae family with chromosome number $2 n=32$. To meet the edible oil requirement of the country, it is one of the best option due to its high oil yield (4-6 $\mathrm{t} /$ ha/year) potential as compared to other annual oil yielding crops (MaryRani, 2015). The oil palm produces five times more oil per hectare per year than the annual oil yielding crops. It has 16 pairs of chromosomes with a genome size of $1.8 \mathrm{~Gb}$ (Singh et al., 2013). 
Oil palm is highly heterozygous in nature, genetic studies aimed at improving the efficiency of oil palm cultivation. Evaluating genetic diversity and characterizing oil palm germplasm plays a crucial role in the genetic improvement of oil palm.

Genetic diversity among germplasm can be measured using morphological, biochemical and molecular techniques (Mohamadi and Prasanna, 2003). Morphological variables have been routinely employed to evaluate genetic diversity among NIFOR oil palm breeding programme (West, 1976, Okwuagwu et al., 2008). Morphological markers are not sufficiently reliable due to low polymorphism, vulnerability to environmental factors and confounding effect of plant developmental stage (Smith and Smith, 1992). Molecular markers are markers of choice duo to their repeatability, high polymorphism, not influenced by environmental factors and developmental stages of plants (Zane et al., 2002). Molecular marker technique includes Isozyme markers (Protein based) and DNA based markers. DNA based markers classified into Hybridization based (RFLP) and PCR based (RAPD, SSR and AFLP). In isozyme analysis, separation of different forms of an enzyme is based on charge. It is having inherent disadvantages like limited number of enzyme loci and developmental and seasonal dependent enzyme expression. The most reliable markers are those based on DNA; these dependent on distinctive structure of the genetic material, and have largely replaced protein markers in genetic studies (Corley and Tinker, 2003).

Molecular markers offer great scope for assessing genetic diversity and relationship among natural population because they are impervious to environmental conditions and are detectable in all stages of plant growth and developments (Mondini et al., 2002). Among the likely alternatives, isozymes are not satisfactorily variable due to low polymorphism ((Purba et al., 2000 and Ghesquiere, 1985). Random amplified polymorphism DNA (RAPD) has also been examined (shah et al., 1994), but poor reproducibility of amplification products limits their generalization in genetic diversity studies (Rafalski, 1997). Other more robust molecular markers such as Restriction fragment length polymorphic DNA (RFLP) (Maizura et al., 2006) are complex: requiring relatively large amount of purified and high molecular weight DNA, time consuming and laborious. Finally, Amplified fragment length polymorphism (AFLP) is a dominant marker which rarely detect heterozygosity and is scored as a presence/absence polymorphism. Molecular markers have been used for different applications like genetic diversity, genotype identification, QTL mapping and marker assisted selection. Assessment of the genetic variation and diversity in oil palm has been carried out based on RAPD (Shah et al., 1994; Rajanaidu et al., 2000; Satish and Mohan Kumar, 2007), AFLP (Kularatne, 2002), Isozymes (Hayati et al., 2004) and RFLP (Maizura et al., 2006). Among these, PCR based SSRs are widely used in any crop improvement programmes and also in oil palm germplasm. Very few efforts have been made in India for genetic diversity among the Indigenous germplasm using molecular markers (Satish and Mohan Kumar, 2007). The data also provide sufficient evidence for identifying each variety, dura, pisifera and tenera separately as well as the parental dura and pisifera together. For the first time to check the level of variability in oil palm varieties DNA based polymorphism assay was performed (Satish and Mohan Kumar, 2007). However, till now no reports on the extent of genetic diversity among the Indigenous oil palm germplasm. Identification of more polymorphic SSR markers is indispensable in utilizing them in genetic diversity, mapping and marker assisted selection programmes. 
Hence in the present study we used 110 SSR markers for identification of polymorphic SSRs for their use in genetic diversity studies in selected genotypes. The present study conducted with the aim of identification of polymorphic SSR markers among a set of oil palm germplasm and genetic diversity analysis of the selected germplasm using polymorphic SSR markers.

\section{Materials and Methods}

\section{Plant materials and DNA extraction}

Total eight oil palm accessions were used and the details of the accessions were given in table 1 . The leaflet of an unopened spear of oil palm in field gene bank was used for genomic DNA extraction (Gawel and Jarret, 1991).

\section{SSR amplification using PCR}

A set of 110 SSR markers were used for amplification in the eight selected genotypes of oil palm. The forward and reverse sequences of the primers were obtained from Billote et al., (2005). Thermal reaction were carried out in a reaction mixture $(20 \mu \mathrm{l})$ consisting of $10 \mathrm{X}$ buffer (Himedia), $2 \mu 1$ having $15 \mathrm{~mm} \mathrm{MgCl}_{2}, 0.2 \mathrm{mM}$ of each forward and reverse primer, $2 \mu 1$ of 2 mMdNTPs, $0.2 \mu \mathrm{l}$ of $1 \mathrm{U}$ of Taq DNA polymerase (Invitrogen, USA) and about 25$50 \mathrm{ng}$ of template DNA. The PCR amplifications were performed in a Thermocycler (Biorad, USA) programmed for an initial denaturation of $3 \mathrm{~min}$ at $95^{\circ} \mathrm{Cfollowed}$ by 35 cycles of $30 \mathrm{~s}$ at $95^{\circ} \mathrm{C}, 30 \mathrm{~s}$ of $50^{\circ} \mathrm{C}$ annealing temperature, extension of 1 $\min$ at $72^{\circ} \mathrm{C}$, with a final extension of $10 \mathrm{~min}$ at $72^{\circ} \mathrm{C}$, and hold at $4{ }^{\circ} \mathrm{C}$. The PCR products were fractioned on $3 \%$ super fine resolution (SFR) agarose gel. The electrophoresis was carried at 100 volts for $3 \mathrm{~h}$ at room temperature. Agarose gel stained with ethidium bromide and visualized using Bioimaging system (Bio Rad) and scoring was carried out manually based on the size of the $100 \mathrm{bp}$ ladder. The statistical analysis of polymorphism and UPGMA analysis for generating dendrogram was done by using power marker v 3.0 (Liu and Muse, 2005). The PIC, heterozygosity, gene diversity, allele frequency and inbreeding co-efficient were calculated using power marker V3.0 software (Liu and Muse, 2005).

\section{Results and Discussion}

The genomic DNA of the oil palm genotypes (Table 1) were amplified using 110 SSR markers and yielded scorable bands. All the 110 SSRs were spread across all the chromosome of oil palm evenly. Out of the 110 primers, $42(38.1 \%)$ loci were found to be polymorphic, and detected 113 alleles with an average of 2.7 alleles per locus while 68 SSR loci $(61.8 \%)$ were monomorphic. The number of alleles generated with polymorphic primers ranged from 2 to 6 among the oil palm genotypes. The SSR loci mEgCIR0779 and $\mathrm{mEgCIR} 0782$ were found to have maximum number of alleles (6 and 5 respectively) followed by the $\mathrm{mEgCIR} 2347$ and mEgCIR0246, mEgCIR0243 and mEgCIR0192. The banding pattern representing the polymorphism of SSR loci were shown in Figure 2a and for SSR loci mEgCIR0779 and mEgCIR0792 in Figure 2b. The PIC value for all the polymorphic primers across eight oil palm genotypes varied from 0.11 to 0.76 with an average value of 0.38 demonstrating their ability to discriminate between individual accessions. The higher the PIC of the marker, the more informativeness of the marker. Out of 42 primers mEgCIR0779 shown highest PIC value of 0.76 , followed by mEgCIR0782 (0.73), $\mathrm{mEgCIR} 2347$ (0.63) and mEgCIR2595 (0.64) and the lowest PIC value was observed in primers mEgCIR3286 (0.11) and SEG00166 $(0.14)$ and followed by SPSC00033 (0.19) and mEgCIR0774 (0.19) (Table 3). 
Table.1 Details of the eight oil palm indigenous accessions used in the study

\begin{tabular}{|c|c|c|c|} 
Sr. No. & Genotypes & IC number & Place of collection \\
\hline $\mathbf{1}$ & Nellore 1 & IC0610025 & Suryapalli, Nellore, Andhra Pradesh \\
\hline $\mathbf{2}$ & TTD-1 & IC0610027 & Theni, Tamilnadu \\
\hline $\mathbf{3}$ & AND-16 & IC0610018 & Krishna nallah, Andaman and Nicobar Islands \\
\hline $\mathbf{4}$ & MANG-1 & ICO610030 & Sulia, Mangalore, Karnataka \\
\hline $\mathbf{5}$ & MANG-6 & IC0610032 & Sulia, Mangalore, Karnataka \\
\hline $\mathbf{6}$ & AND-24 & ICO610024 & Krishna nallah, Andaman and Nicobar Islands \\
\hline $\mathbf{7}$ & NELLORE-2 & IC00610026 & Suryapalli, Nellore, Andhra Pradesh \\
\hline $\mathbf{8}$ & MANG-2 & IC00610031 & Sulia, Mangalore, Karnataka \\
\hline
\end{tabular}

Table.2 SSR markers used to assess genetic diversity in eight oil palm indigenous genotypes

\begin{tabular}{|c|c|c|c|c|c|c|}
\hline $\begin{array}{l}\text { Sr. } \\
\text { No. }\end{array}$ & $\begin{array}{c}\text { SSR } \\
\text { MARKER }\end{array}$ & Forward primer $\left(5^{\prime} \mathbf{3}^{\prime}\right)$ & Reverse primer ( $\left.3^{\prime}-5^{\prime}\right)$ & $\begin{array}{c}\text { Annealing } \\
\text { temperature }\left({ }^{\circ} \mathbf{C}\right)\end{array}$ & Repeat Motif & $\begin{array}{l}\text { Linkage } \\
\text { group }\end{array}$ \\
\hline 1 & SEG00113 & GTCACCGAACCCTAATAAAAT & ATGCAGTTGAGGACAAAAAG & & & \\
\hline 2 & $\mathrm{mEgCIR} 0268$ & GCAACACCATTAGAGAGA & TCCATGCATCCAAACAG & 52 & (GA) 12 & 1 \\
\hline 3 & mEgCIR0163 & ATGCATGTGATTTTATTAGGTGAGA & CGACCCTCAGTCAATCAGTAAG & 52 & (GA) 23 & 8 \\
\hline 4 & mEgCIR0246 & GGTAAGAGATGAGATGGGTTGTC & AGGAATTAAGGGTTGTAGGTGAA & 52 & (GA) 19 & 8 \\
\hline 5 & mEgCIR0243 & TGGAACTCCTATTTTACTGA & GCCTCGTAATCCTTGTCA & 52 & (GA) 17 & 10 \\
\hline 6 & mEgCIR0192 & AAGCTAGCGACCTATGATTTTAGA & AAACAAGTAATGTGCATAACCTTTC & 52 & (GA) 18 & 11 \\
\hline 7 & mEgCIR0037 & CCAGTCTGCTAACCATCCTATAC & ТСТСАСТТССТССССАСАТС & 52 & (GA) 17 & 15 \\
\hline 8 & $\mathrm{mEgCIR0177}$ & TGAATGTGTGTGCAATGTGTAT & ATAGTCAATAATCGTAGGAAAATG & 52 & $(\mathrm{GA}) 20$ & 15 \\
\hline 9 & SMG00210 & СТTTTCССТCATCTCTGCTTC & CGTCTACCTTGTTTAGCTGTTGT & nil & nil & nil \\
\hline 10 & SMG00217 & GGTGGAATTAGTTGCTCAGAAG & CGCAGATGTTTCATAATCGAG & nil & nil & nil \\
\hline 11 & SPSC00163 & GGTGGAATTAGTTGCTCAGAAG & CGCAGATGTTTCATAATCGAG & nil & nil & nil \\
\hline 12 & SPSC00033 & ATGGTCCCGTCCTAGGATTT & AACAGCTTGCCTCCTTGGTA & nil & nil & nil \\
\hline 13 & mEgCIR0894 & TGCTTCTTGTCCTTGATACA & CCACGTCTACGAAATGATAA & 52 & (GA) 18 & 7 \\
\hline 14 & mEgCIR0555 & TACCATCACTGACCAATAAC & GTCTTTCTTGCTAACTACAC & 52 & (GA) 18 & 8 \\
\hline 15 & mEgCIR0774 & TGGCCGAGGCAGAAGAAAAT & GCTTGGTGGGTAAGCTGGATTATT & 52 & (GA)20 & 8 \\
\hline 16 & SMG00156 & GGTGTCATAACTTCGTTGTTGCT & ATGCTCAAAAGTGGGTTTCTCTC & nil & nil & nil \\
\hline 17 & SEG00166 & CATGCGTCGTCAATAAATGG & TGCTACCAACAATCCAGAGAAG & nil & nil & nil \\
\hline 18 & SMG00155 & AACCCAACCCAATCAACATTAG & GACACAGATAAAAAGGTCCAG & nil & nil & nil \\
\hline 19 & mEgCIR0886 & GATCTGCCGGTGCTCCTA & CTCAGTTTAGTCGATCCTTCCATTG & 52 & $(\mathrm{GA}) 9$ & 8 \\
\hline 20 & $\mathrm{mEgCIR} 0878$ & CAAAGCAACAAAGCTAGTTAGTA & CAAGCAACCTCCATTTAGAT & 52 & (GA)22 & 11 \\
\hline 21 & mEgCIR0465 & TCCCCCACGACCCATTC & GGCAGGAGAGGCAGCATTC & 58 & (CCG) 4 & 12 \\
\hline 22 & mEgCIR0790 & TTGGTGGTCCTTTTGAATATC & ACAAACCCAGCACTTAAAATAAC & 52 & (GA) 19 & 12 \\
\hline 23 & mEgCIR0779 & AATGCAGACCAAGCTAATCATATAC & GTTCAGGTGATGGTGACTCAGATAG & 52 & (CA)11 (GA)22 & 14 \\
\hline 24 & $\mathrm{mEgCIR} 0773$ & GCAAAATTCAAAGAAAACTTA & CTGACAGTGCAGAAAATGTTATAGT & 52 & (GT)7 (GA)8 & 15 \\
\hline 25 & $\mathrm{mEgCIR} 0782$ & CGTTCATCCСАCСАССТTTC & GCTGCGAGGCCACTGATAC & 56 & $(\mathrm{GA}) 20$ & 16 \\
\hline 26 & mEgCIR1713 & GCTGAAGATGAAATTGATGTA & TTCAGGTCCACTTTCATTTA & 52 & (GTAT) $3(\mathrm{GT}) 12$ & 1 \\
\hline 27 & $\mathrm{mEgCIR} 2575$ & GGGACTTCGCAAACTGTAGCA & CGGTGGCGTATGGTGGATT & 52 & $(\mathrm{GA}) 5$ & 2 \\
\hline 28 & $\mathrm{mEgCIR} 2347$ & ATTTTGCATGTGTTGAGAGC & CAACCAATTGCACCCTAAAG & 52 & (GA) 15 & 3 \\
\hline 29 & $\mathrm{mEgCIR} 2518$ & GATCCCAATGGTAAAGACT & AAGCCTCAAAAGAAGACC & 52 & (GT)6 (GA)32 & 3 \\
\hline 30 & mEgCIR2595 & TCAAAGAGCCGCACAACAAG & ACTTTGCTGCTTGGTGACTTA & 52 & (GA)16 & 4 \\
\hline 31 & mEgCIR2813 & GCTTTGTTGCAGTTTGACTA & GTTTAGGATGTTGCGTGAT & 52 & (GT)7 (GA)11 & 5 \\
\hline 32 & $\mathrm{mEgCIR} 1773$ & ATGACCTAAAAATAAAATCTCAT & ACAGATCATGCTTGCTCACA & 52 & (CT) $14(\mathrm{GT}) 21$ & 12 \\
\hline 33 & $\mathrm{mEgCIR} 3286$ & GTTTATCATTTTGGGGTCAG & CGGTGTCCCTCAGGATGTA & 52 & $(\mathrm{GA}) 19$ & 4 \\
\hline 34 & mEgCIR3232 & GTGAGCGATTGAGGGGTGTG & GGGGCTTGATTGAGTATTTCCA & 56 & $(\mathrm{GA}) 9$ & 4 \\
\hline 35 & $\mathrm{mEgCIR} 3281$ & TTTCTTATGGCAATCACACG & GGAGGGCAGGAACAAAAAGT & 52 & (GA) 17 & 6 \\
\hline 36 & $\mathrm{mEgCIR} 3358$ & CCAAGGAACAACATAGA & GTTCCCATCCTATTAGAC & 52 & (GA) 15 & 6 \\
\hline 37 & mEgCIR3383 & AGCAAGACACCATGTAGTC & GACACGTGGGATCTAGAC & 52 & (GA)21 & 6 \\
\hline 38 & mEgCIR3293 & ACAACCACAAGAGTCCTAAC & CTGCGAAATCATAAAAAGTA & nil & nil & nil \\
\hline 39 & $\mathrm{mEgCIR} 3111$ & TTTCTCATGGTGGGTAGGTG & TCAGATTGCGGTGGATGTAT & 52 & (GA)15 & 12 \\
\hline 40 & $\mathrm{mEgCIR} 3328$ & GAGGGGGTTGGGACATTAC & TAGCTCACAACCCAGAATCTAT & 52 & $(\mathrm{GA}) 22$ & 8 \\
\hline 41 & $\mathrm{mEgCIR} 3376$ & СССТСССТGCTAССТTСТ & TTATGTGAGTGCCTTTGATG & 52 & (GA) 19 & 8 \\
\hline 42 & mEgCIR3305 & ACTTGCACCACTACTTCTAT & CTTTTAGGCATTCTCTTGTAG & 52 & (GA) 15 & 9 \\
\hline
\end{tabular}


Int.J.Curr.Microbiol.App.Sci (2018) 7(4): 333-341

Table.3 Parameters for genetic analysis of 42 SSR loci across the eight oil palm genotypes

\begin{tabular}{|c|c|c|c|c|c|}
\hline SSR Marker & Major Allele Frequency & Allele Number & Gene Diversity & Heterozygosity & PIC \\
\hline SEG00113 & 0.69 & 2.00 & 0.43 & 0.13 & 0.34 \\
\hline mEgCIR0268 & 0.86 & 2.00 & 0.24 & 0.00 & 0.21 \\
\hline mEgCIR0163 & 0.86 & 2.00 & 0.24 & 0.00 & 0.21 \\
\hline mEgCIR0246 & 0.69 & 2.00 & 0.43 & 0.13 & 0.34 \\
\hline mEgCIR0243 & 0.38 & 3.00 & 0.66 & 0.25 & 0.58 \\
\hline mEgCIR0192 & 0.44 & 3.00 & 0.63 & 0.38 & 0.56 \\
\hline mEgCIR0037 & 0.75 & 2.00 & 0.38 & 0.00 & 0.30 \\
\hline mEgCIR0177 & 0.44 & 3.00 & 0.65 & 0.38 & 0.57 \\
\hline SMG00210 & 0.50 & 2.00 & 0.50 & 0.33 & 0.38 \\
\hline SMG00217 & 0.63 & 3.00 & 0.53 & 0.00 & 0.47 \\
\hline SPSC00163 & 0.64 & 2.00 & 0.46 & 0.71 & 0.35 \\
\hline SPSC00033 & 0.88 & 2.00 & 0.22 & 0.00 & 0.19 \\
\hline mEgCIR0894 & 0.63 & 2.00 & 0.47 & 0.00 & 0.36 \\
\hline mEgCIR0555 & 0.50 & 3.00 & 0.55 & 0.88 & 0.46 \\
\hline mEgCIR0774 & 0.88 & 2.00 & 0.22 & 0.00 & 0.19 \\
\hline SMG00156 & 0.79 & 3.00 & 0.36 & 0.14 & 0.33 \\
\hline SEG00166 & 0.92 & 2.00 & 0.15 & 0.17 & 0.14 \\
\hline SMGG0155 & 0.50 & 2.00 & 0.50 & 0.00 & 0.38 \\
\hline mEgCIR0886 & 0.58 & 2.00 & 0.49 & 0.50 & 0.37 \\
\hline mEgCIR0878 & 0.56 & 2.00 & 0.49 & 0.13 & 0.37 \\
\hline mEgCIR0465 & 0.56 & 2.00 & 0.49 & 0.13 & 0.37 \\
\hline mEgCIR0790 & 0.57 & 2.00 & 0.49 & 0.00 & 0.37 \\
\hline mEgCIR0779 & 0.31 & 6.00 & 0.79 & 0.63 & 0.76 \\
\hline mEgCIR0773 & 0.75 & 3.00 & 0.40 & 0.13 & 0.35 \\
\hline mEgCIR0782 & 0.29 & 5.00 & 0.77 & 0.43 & 0.73 \\
\hline mEgCIR1713 & 0.64 & 4.00 & 0.54 & 0.14 & 0.50 \\
\hline mEgCIR2575 & 0.75 & 3.00 & 0.41 & 0.25 & 0.37 \\
\hline mEgCIR2347 & 0.43 & 4.00 & 0.68 & 0.14 & 0.63 \\
\hline mEgCIR2518 & 0.75 & 4.00 & 0.41 & 0.38 & 0.39 \\
\hline mEgCIR2595 & 0.43 & 4.00 & 0.69 & 0.00 & 0.64 \\
\hline mEgCIR2813 & 0.83 & 2.00 & 0.28 & 0.00 & 0.24 \\
\hline mEgCIR1773 & 0.81 & 3.00 & 0.32 & 0.13 & 0.29 \\
\hline mEgCIR3286 & 0.94 & 2.00 & 0.12 & 0.13 & 0.11 \\
\hline mEgCIR3232 & 0.81 & 3.00 & 0.32 & 0.13 & 0.29 \\
\hline mEgCIR3281 & 0.86 & 2.00 & 0.24 & 0.00 & 0.21 \\
\hline mEgCIR3358 & 0.56 & 3.00 & 0.59 & 0.38 & 0.52 \\
\hline mEgCIR3383 & 0.50 & 3.00 & 0.62 & 0.13 & 0.54 \\
\hline mEgCIR3293 & 0.75 & 3.00 & 0.38 & 0.00 & 0.30 \\
\hline mEgCIR3111 & 0.81 & 3.00 & 0.32 & 0.13 & 0.29 \\
\hline mEgCIR3328 & 0.63 & 2.00 & 0.47 & 0.00 & 0.36 \\
\hline mEgCIR3376 & 0.69 & 0.43 & 0.13 & 0.34 \\
\hline mEgCIR3305 & 0.50 & 0.59 & 0.00 & 0.51 \\
\hline & & & & \\
\hline
\end{tabular}




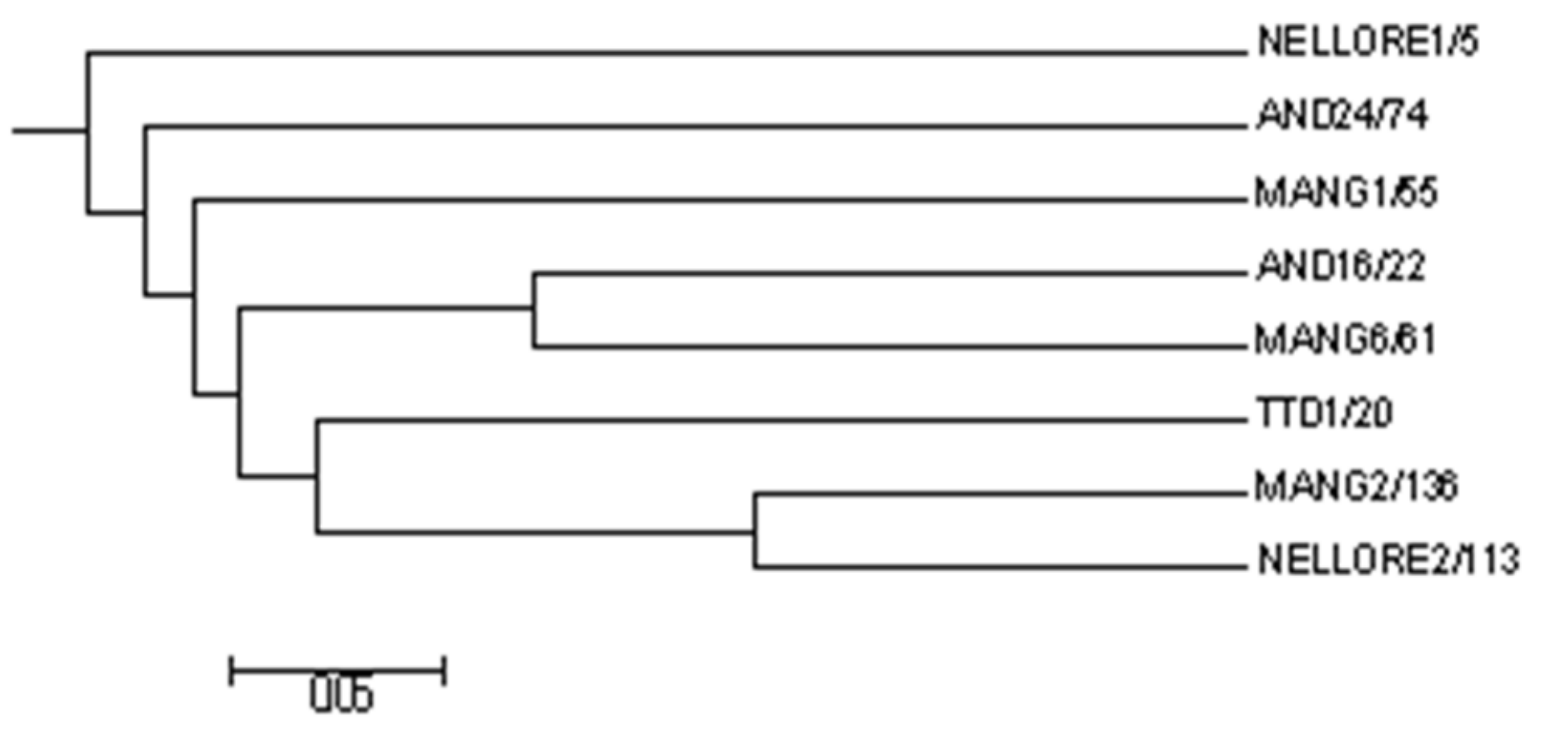

Fig. 1: The dendrogram of eight oil palm genotypes as obtained from POWER Marker softw are based on UPGMA an alysis

Fig.2a The SSR banding profile of mEgCIR0246, mEgCIR0243 and mEgCIR0192 loci among the eight oil palm genotypes. M-Marker (100bp), lane (1-8) oil palm genotypes (for label please refer Table 1)

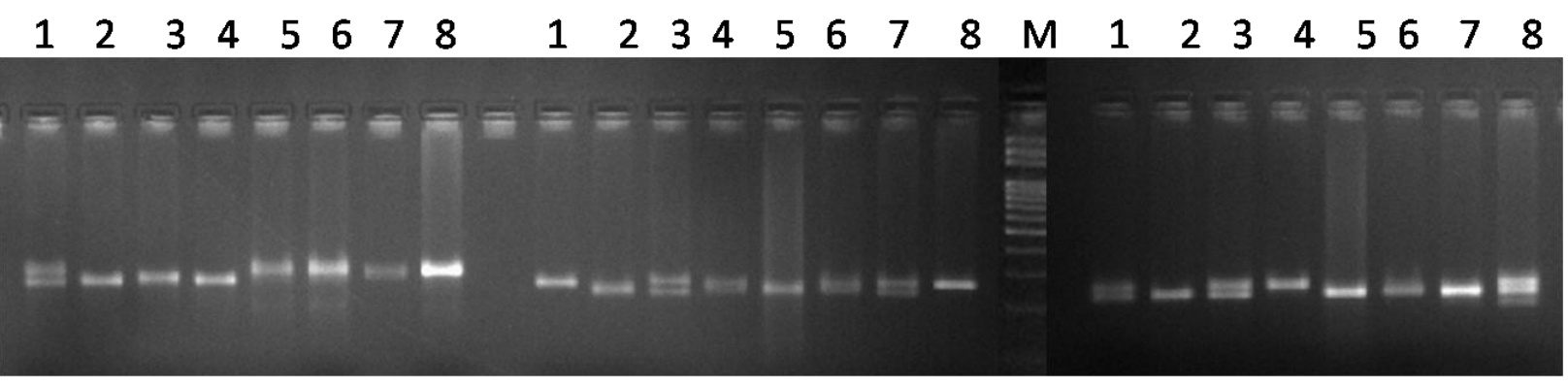

Fig.2b The SSR banding profile of mEgCIR0779 and mEgCIR0782 loci among the 8 oil palm genotypes. M-Marker (100bp), lane (1-8) oil palm genotypes (for label please refer Table 1)

\section{$\begin{array}{llllllllllllllllll}M & 1 & 2 & 3 & 4 & 5 & 6 & 7 & 8 & M & 1 & 2 & 3 & 4 & 5 & 6 & 7 & 8\end{array}$}

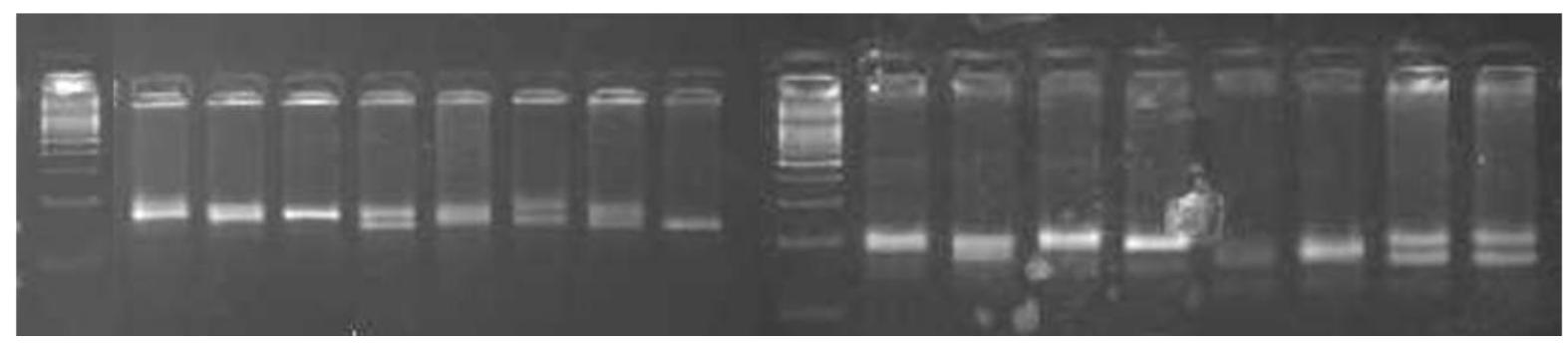


Gene diversity also known as expected heterozygosity $(\mathrm{He})$ was in the range of 0.12 (mEgCIR3286) to 0.79 (mEgCIR0779) with an average value of 0.45 . The heterozygosity, known as observed heterozygosity (Ho) was observed with an average of 0.18 and range of 0.00 to 0.88 ( $\mathrm{mEgCIR} 0555)$. Major alleles with highest frequency were observed for the locus $\mathrm{mEgCIR} 3286(100 \mathrm{bp})$ at $94 \%$ followed by the locus SEG00166 (100 bp) at 92\%. The ability to provide distance measures between the genotypes that reflect pedigree relatedness ensures a more stringent evaluation of the adequacy of a maker profile data. The fact that minimum genetic distance revealed during the study is a good indication confirming the power of SSR markers to distinguish between geographically similar genotypes and closely related genotypes. The average gene diversity existing among all the genotypes were relatively high (45\%), indicating existence of high levels of polymorphisms among the genotypes.

The dendrogram generated through UPGMA analysis grouped all the eight oil palm genotypes into two major groups. Nellore 1 genotype formed a separate cluster and other all viz. And-2, And-16, Mang-1, Mang-6 and Mang-2, TTD1 and Nellore 2 formed another cluster (Fig. 1).

Allelic frequencies at each locus varied from population to population and some alleles occurred only in one or some populations. In an out-crossing plant like oil palm where random mating is expected, genetic drift and reproductive isolation are the most common factors that affect allele frequencies (Bakoume et al., 2009).

The expected heterzygosity of 0.79 was similar to 0.78 reported as high by Okoyo et al., (2016a) for Elaeis guineensis. The high genetic diversity observed might have resulted from the out crossing behavior of oil palm as earlier reported on Quercus petraea (Cottrell et al., 2003). In genetic diversity analysis $\mathrm{He}$ and Ho results are in close agreement with the findings reported among oil palm genotypes using SSR markers by Okoyo et al., (2016a). They reported range of $\mathrm{He}$ and $\mathrm{Ho}$ of 0.167-0.778 and 0.153 to 0.643 respectively, from Nigeria and Malaysia. Okoyo et al., (2016b) reported He of 0.70 and Ho of 0.69 with NIFOR oil palm germplasm. Out of 110 SSRs 42 were Polymorphic and 68 were monomorphic. The gel picture shows the banding pattern of polymorphic SSRs given in figure 2.

The number of SSR loci based on PIC value with more than the average was 16 in number. Among them, SSR loci mEgCIR0779, mEgCIR0792, mEgCIR2347 and mEgCIR2595 were noteworthy due to their relatively highly level of polymorphism. A total of 16 SSR loci came under the PIC range of 0.38-0.76 with an average value of 0.54 while 26 loci came within the PIC range of 0.11-0.37 with an average value of 0.29 . The higher the PIC of the marker, the more informativeness of the marker. Out of 42 primers mEgCIR0779 shown highest PIC value of 0.76 , followed by $\mathrm{mEgCIR0782}$ (0.73), mEgCIR2347 (0.63) and mEgCIR2595 (0.64), the PIC obtained in this study is within the range of the previous studies in oil palm using SSR markers. Okoyo et al., (2016a) obtained an extremely high mean percentage polymorphism (85.09 \%) and Arias et al., (2012) reported maximum PIC value with 0.822 in commercial oil palm material.

The dendrogram developed eight different genotypes into two major group, this may be due to same parentage might be involved in crossing of the oil palm breeding programme and these geographical zones might have derived from one or similar genetic background (s), similar results were found in Bakoume et al., (2009) study in oil palm (Elaeis guineensis) natural population using SSR markers. Oil palm is highly heterozygous and it has originated from only four oil palm initially so same genes might have played role in this clustering pattern.

Oil palm is an important crop for vegetable oil and there is need of identification of polymorphic markers for identification of important QTLs in germplasm for further usage 
in breeding programme for improving oil yield. In my study identified four highly polymorphic SSR markers (mEgCIR0779, mEgCIR0782, $m E g C I R 2347 \&$ mEgCIR2595) based on the parameters like PIC value of $\geq 63$, gene diversity of $\geq 68 \&$ polymorphic alleles of $\geq 4$. These polymorphic primers can effectively be used in further molecular breeding programs and QTL mapping studies of oil palm since they exhibited very high polymorphism over other loci in the oil palm breeding programme.

\section{Acknowledgment}

First author is thankful to the Directors, ICARIndian Institute of Oil Palm Research, Pedavegi, Andhra Pradesh and University of Horticultural Sciences, Bagalkot, Karnataka for providing the facilities to conduct my research in the Institute as a part of my Ph.D work.

\section{References}

Arias D, Montaya C, Rey L, Romero H (2012) Genetic similarity among commercial oil palm materials based on microsatellite markers. Agronomi and Colombiana 30(2):188-195

Bakoume C, Wickneswari R, Rajanaidu N, Kushairi A, Billotte N (2009) Screening natural il Palm (Elaeis guineensis Jacq.) populations using SSR markers. In: International society for oil palm breeders seminar kuala Lumpur Malaysia. http://isopb.org/?kit=links\& memuid=6, pp 1-10

Billotte N, Marseillac N, Risterucci AM, Adon B, Brottier P, Baurens FC, Singh R, Gerran A, Asmady H, Billot C, Amblard $\mathrm{P}$, et al., (2005) Microsatellite-based high density linkage map in oil palm (Elaeis guineensis Jacq.). Theor Appl Genet 110:754-765

Corley RHV, Tinker PB (2003) Molecular markers in oil palm breeding. The Oil palm forth edition $\mathrm{pp} 163$

Cottrell JE, Munro RC, Tabbener HE, Milner AD, Forrest GI, Lowe AJ (2003)
Comparison of fine-scale genetic structure using nuclear microsatellites within two British oakwoods differing in population history. For Ecol Manag 176: 287-303.

Gawel N, Jarret R (1991) A modified CTAB DNA extraction protocol for Musa and Ipomea. Plant Mol Biol., 9: 262-266

GhesquiereM (1985) Enzyme polymorphism in oil palm (Elaeis guineensis Jacq) II Variability and genetic structure of seven origins of oil palm. Oleagineux 40: 529540

Hayati A, Wickneswari R, Maizura I, Rajanaidu N (2004) Genetic diversity of oil palm (Elaeis guineensis Jacq) germplasm collections from Africa: implications for improvement and conservation of genetic resources. Theor. Appl Genet., 108: 12741284

Kularatne RS (2000) Assessment of genetic diversity in natural oil palm (Elaeis guineensis Jacq.) using amplified fragment length polymorphism markers. $\mathrm{PhD}$ thesis, Universiti Kebangsaan Malaysia, Bangi.

Liu K, Muse, SV (2005) Powermarker: integrated analysis environment for genetic marker data. Bioinformatics 21(9): 2128-2129

Maizura I, Rajanaidu N, Zakri AH, Cheah SC (2006) Assessment of genetic diversity in oil palm (Elaeis guineensis Jacq) using restriction fragment length polymorphism (RFLP). Genetic Resources and Crop Evolution. 53:187-1295

MaryRani KL (2015) Global and National Scenario of Oil palm. Compendium of lectures on oil palm Production technology, ICAR-Indian Institute of oil Palm Research, Pedavgi, West Godavari District, Andhra Pradesh.

Mohammadi SA, Prasanna BM (2003) Analysis of genetic diversity in crop plant salient statistical tools and considerations. Review and Interpretation. Crop Science, 43:1235-1248 
Mondini L, Noorani A, Pagnotta, MA (2009) Assessing Plant Genetic Diversity by Molecular Tools. Diversity1:19-35

Okoye MN, Uguru MI, Bakoume C, Singh R, Okwuagawu CO (2016b) Assessment of genetic diversity of NIFOR oil palm main breeding parent genotypes using microsatellite markers. American Journal of Plant Sciences 7:218-237

Okoyo MN, Bakoume C, Uguru MI, Singh R, Okwuagawu CO (2016a) Genetic relationships between elite oil palms from Nigeria and selected breeding and germplasm materials from Malaysia via simple sequence repeat (SSR) markers. Journal of Agricultural Sciences 8(2):159178

Okwuagwu CO, Okoye MN, Okolo EC, Ataga CD, Uguru MI (2008) Genetic variability of fresh fruit bunch yield in Deli/dura $\mathrm{x}$ tenera breeding populations of oil palm (Elaeis guineensis Jacq.) in nigeria. Journal of Tropical Agriculture 46(12):40-45

Purba AR, Noyer JL, Baudouin L, Perrier X, Hamon S, Lagoda PJL (2000) A new aspect of genetic diversity if Indonesian oil palm (Elaeis guineensis Jacq) revealed by isozymes and AFLP markers and its consequences for breeding. Theoretical and Applied Genetics 101:956-961

Rafalski JA (1997) Randomly Amplified Polymorphic DNA (RAPD) Analysis. In: caerano-Anolles G, Gresshoff P.M, Eds, DNA markers Protocols, Applications and Overviews, Wiley-Vch, New York, $75-83$
Rajanaidu N, Maizura I, Cheah SC (2000) Screening of oil palm natural populations using RAPD and RFLP molecular markers. In: Rajanaidu, N, Ariffin D (eds) Proceedings of International Symposium on Oil Palm Genetic Resources and Utilization, Kuala Lumpur, pp AA1AA28

Satish DK, Mohankumar C (2007) RAPD markers for identifying oil palm (Elaeis guineensis Jacq.) parental varieties (dura \&pisifera) and the hybrid Tenera. Indian Journal of Biotechnology.6:354-358

Shah FH, Rashid O, Simons AJ, Dunsdon A (1994) The utility of RAPD markers for the determination of genetic variation in oil palm (Elaeis guineensis). Theor Appl Genet 89:713-718

Singh R, Ong-Abdullah M, Low ET, Manaf MA, Rosli R, Nookiah R, Ooi SE, Chan KL, Halim MA, et al., (2013) Oil palm genome sequence reveals divergence of interfertile species in old and new worlds. Nature 500:335-339.

Smith JSC, Smith OS (1992) Fingerprinting crop varieties. Advanced Agronomy 47:85-140

West MJ (1976) The analysis of the bunch yield data of the NIFOR oil palm breeding programme and the choice of new parental material. A supplementary report of the ministry of overseas development on research project. R2354 Mimeo (pp.41)

Zane L, Bargelloni L, Patarnello T (2002) Strategies for microsatellite isolation a review. Mol Ecol 11:1-16.

\section{How to cite this article:}

Bhagya, H.P., B. Kalyana Babu, Mahanthesha B.N. Naika, R.K. Mathur, P.M. Gangadharappa, D. Satisha and Naik, R.B. 2018. Identification and Utilization of Polymorphic SSR Markers for Genetic Diversity Studies in Oil Palm. Int.J.Curr.Microbiol.App.Sci. 7(04): 333-341. doi: https://doi.org/10.20546/ijcmas.2018.704.038 